OPEN ACCESS

Edited by:

Anders Omsland

Washington State University, USA

Reviewed by:

Michael F. Minnick,

The University of Montana, USA

Irving Coy Allen,

Virginia Tech, USA

*Correspondence:

Edward I. Shaw

ed.shaw@okstate.edu

Received: 16 October 2016 Accepted: 02 December 2016 Published: 19 December 2016

Citation:

Mahapatra S, Gallaher B, Smith SC, Graham JG, Voth DE and Shaw EI (2016) Coxiella burnetii Employs the Dot/lcm Type IV Secretion System to Modulate Host NF- $\kappa$ B/RelA Activation.

Front. Cell. Infect. Microbiol. 6:188 doi: 10.3389/fcimb.2016.00188

\section{Coxiella burnetii Employs the Dot/lcm Type IV Secretion System to Modulate Host NF-кB/RelA Activation}

\author{
Saugata Mahapatra ${ }^{1}$,Brandi Gallaher ${ }^{1}$, Sydni Caet Smith ${ }^{1}$, Joseph G. Graham ${ }^{2}$, \\ Daniel E. Voth ${ }^{2}$ and Edward I. Shaw ${ }^{1 *}$ \\ ${ }^{1}$ Department of Microbiology and Molecular genetics, Oklahoma State University, Stillwater, OK, USA, ${ }^{2}$ Department of \\ Microbiology and Immunology, University of Arkansas for Medical Sciences (UAMS), Little Rock, AR, USA
}

Coxiella burnetii is the causative agent of $Q$ fever and an obligate intracellular pathogen in nature that survives and grows in a parasitophorous vacuole (PV) within eukaryotic host cells. C. burnetii promotes intracellular survival by subverting apoptotic and pro-inflammatory signaling pathways that are typically regulated by nuclear transcription factor-kB (NF-kB). We and others have demonstrated that $C$. burnetii NMII proteins inhibit expression of pro-inflammatory cytokines and induce expression of anti-apoptotic genes during infection. Here, we demonstrate that $C$. burnetii promotes intracellular survival by modulating NF-kB subunit p65 (RelA) phosphorylation, and thus activation, in a Type Four B Secretion System (T4BSS)-dependent manner. Immunoblot analysis of RelA phosphorylated at serine-536 demonstrated that C. burnetii increases NF-кB activation via the canonical pathway. However, RelA phosphorylation levels were even higher in infected cells where bacterial protein or mRNA synthesis was inhibited. Importantly, we demonstrate that inhibition of RelA phosphorylation impairs $\mathrm{PV}$ formation and C. burnetii growth. We found that a T4BSS-defective mutant (Cb $\Delta$ dotA) elicited phosphorylated RelA levels similar to those of wild type $C$. burnetii infection treated with Chloramphenicol. Moreover, cells infected with $\mathrm{Cb} \Delta$ dotA or wild type $\mathrm{C}$. burnetii treated with Chloramphenicol showed similar levels of GFP-RelA nuclear localization, and significantly increased localization compared to wild type C. burnetii infection. These data indicate that without de novo protein synthesis and a functional T4BSS, C. burnetii is unable to modulate NF-кB activation, which is crucial for optimal intracellular growth.

Keywords: Coxiella burnetii, NF-кB, type four secretion system, obligate intracellular, Q fever

\section{INTRODUCTION}

Coxiella burnetii is a Gram-negative intracellular bacterial pathogen and the causative agent of Q fever in humans (Maurin and Raoult, 1999; Miller et al., 2006). Acute Q fever typically manifests as a self-limiting flu-like illness, with symptoms ranging from sub-clinical to debilitating, and can be fatal (Maurin and Raoult, 1999; Miller et al., 2006; Toman et al., 2012). Common chronic sequelae include endocarditis, hepatitis, and a chronic fatigue syndrome (Maurin and Raoult, 1999; Miller et al., 2006; Toman et al., 2012). Several recent Q fever outbreaks around the world exhibit the 
organism's global reach (Karakousis et al., 2006; Enserink, 2010; Dijkstra et al., 2012; Toman et al., 2012; Wielders et al., 2015). C. burnetii is environmentally stable, acquired through aerosolization, has a low infectious dose (Moos and Hackstadt, 1987), and is classified as a category B select agent (Maurin and Raoult, 1999; McQuiston and Childs, 2002; McQuiston et al., 2002; Miller et al., 2006; Toman et al., 2012). Upon inhalation, C. burnetii infects alveolar macrophages and replicates within a host cell-derived parasitophorous vacuole (PV) that retains many characteristics of phagolysosomes (Heinzen et al., 1999; Voth and Heinzen, 2007, 2009; van Schaik et al., 2013). The C. burnetii infectious cycle is $\sim 6$ days long (Coleman et al., 2004) and is highlighted by (i) invasion of the host cell by the environmentally stable Small Cell Variant (SCV) form of the bacterium, (ii) development of an acidified PV $(\mathrm{pH}<5)$, (iii) differentiation of C. burnetii SCVs into replicative Large Cell Variants (LCVs), (iv) PV enlargement and logarithmic pathogen growth, (v) asynchronous LCV to SCV differentiation beginning around 6 days post infection (dpi), and (vi) eventual cell exit (Heinzen et al., 1999; Coleman et al., 2004; Voth and Heinzen, 2007).

Intracellular bacteria including C. burnetii promote infection by targeting and modulating multiple host cell molecular processes (Bhavsar et al., 2007; Böhme and Rudel, 2009; Voth and Heinzen, 2009; Lamkanfi and Dixit, 2010; van Schaik et al., 2013). Manipulation of host nuclear transcription factor NF- $\kappa \mathrm{B}$ signaling is a common strategy used by microbial pathogens to thwart host innate and adaptive immune responses (Bhavsar et al., 2007; Rahman and McFadden, 2011). NF- $\mathrm{B}$ is a vital regulator of genes involved in pro-inflammatory immune response, cell proliferation, and apoptosis (Beinke and Ley, 2004; Bonizzi and Karin, 2004; Hoffmann and Baltimore, 2006; Perkins, 2007; Rahman and McFadden, 2011). During normal

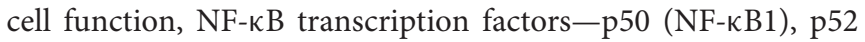
(NF-кB2), p65 (RelA), cRel, and RelB remain in the cytoplasm bound to the IкB inhibitory protein and are activated either via canonical or non-canonical signaling pathways (Beinke and Ley, 2004; Bonizzi and Karin, 2004; Hoffmann and Baltimore, 2006; Perkins, 2007; Rahman and McFadden, 2011). In either case, NF- $\kappa \mathrm{B}$ activation and nuclear accumulation leads to inflammatory and immunomodulatory responses (Beinke and Ley, 2004; Bonizzi and Karin, 2004; Hoffmann and Baltimore, 2006; Perkins, 2007; Rahman and McFadden, 2011). NF-кB transcriptional factors regulate expression of hundreds of genes linked to the innate and adaptive immune response as well as diverse cellular processes such as proliferation, differentiation, and death (Beinke and Ley, 2004; Bonizzi and Karin, 2004; Hoffmann and Baltimore, 2006; Perkins, 2007; Rahman and McFadden, 2011). C. burnetii affects multiple host cell pathways regulated by NF-кB (Voth et al., 2007; Mahapatra et al., 2010). We previously demonstrated that de novo C. burnetii protein synthesis modulates expression of a subset of NF- $\kappa \mathrm{B}$-regulated inflammatory cytokine genes (IL8, CCL2, CXCL1, and SPP1) (Mahapatra et al., 2010). C. burnetii protein(s) actively reduces the RNA level of these genes relative to those found in cells containing bacteria transiently inhibited with Chloramphenicol (Cm) (Mahapatra et al., 2010). Interestingly, even though the host innate immune system is unable to contain primary C. burnetii infection, NF- $\mathrm{B}$-dependent cytokine production is commonly reported (Raoult and Marrie, 1995; Meghari et al., 2005, 2006, 2008; Soraya Meghari et al., 2006; Benoit et al., 2008). For example, C. burnetii stimulates an atypical M2 form of activation (Benoit et al., 2008). M2 cells typically have an IL-12 ${ }^{\text {low }}$, IL$23^{\text {low }}$, IL-10 high phenotype with a variable capacity to produce inflammatory chemotactic cytokines (Benoit et al., 2008). Other prominent NF- $\kappa \mathrm{B}$-dependent cytokines induced by $C$. burnetii include TNF- $\alpha$, IL-1 $\beta$, IFN- $\gamma$, RANTES, MCP-1, SCYA3, SCYA4, and IL-8 (Raoult and Marrie, 1995; Ren et al., 2003; Meghari et al., 2005, 2006, 2008; Soraya Meghari et al., 2006; Benoit et al., 2008; Mahapatra et al., 2010; Amara et al., 2012; Schoffelen et al., 2014; Graham et al., 2016). In addition, C. burnetii regulates host apoptosis at the transcriptional level by altering expression of NF- $\mathrm{BB}$-mediated cell survival-related genes (cIAP2 and $a 1 /$ bfl-1) (Voth et al., 2007). Moreover, avirulent C. burnetii activates Toll like receptor 2 (TLR-2) that typically signals via the NF-кB pathway (Zamboni et al., 2004). Therefore, existing data clearly suggest that NF- $\kappa$-dependent host cell processes are targeted by C. burnetii. However, essentially nothing is known about how $C$. burnetii modulates NF-кB signaling or its importance to the pathogen for intracellular survival and replication.

Intracellular bacterial pathogens including $C$. burnetii manipulate eukaryotic cell functions by secreting bacterial proteins, or effectors, that interact with host cell factors to promote intracellular survival (Voth and Heinzen, 2009; Voth et al., 2009, 2011; Toman et al., 2012; van Schaik et al., 2013; Newton et al., 2014). C. burnetii produces a T4BSS, and bacterially-derived virulence determinants are delivered to the host cytosol via this machinery throughout infection (Voth and Heinzen, 2009; Chen et al., 2010; Toman et al., 2012; van Schaik et al., 2013). Employing bioinformatics, bacterial two-hybrid approaches, yeast screens, and genetic screens, approximately 120 putative C. burnetii T4BSS effectors have been identified (Voth et al., 2009; Chen et al., 2010; van Schaik et al., 2013; Newton et al., 2014). However, it remains unknown whether the C. burnetii T4BSS modulates NF-кB signaling. Many immune responses seen in in vitro and in vivo C. burnetii studies have been attributed to LPS and intrinsic properties of the bacterium (Honstettre et al., 2004; Zamboni et al., 2004; Shannon et al., 2005a,b; Andoh et al., 2007; Zhang et al., 2007; Lu et al., 2008). These approaches have not addressed the possibility that $C$. burnetii actively modulates the NF$\kappa \mathrm{B}$-mediated immune response at the cellular level using the T4BSS. We hypothesized that C. burnetii modulates host NF-кB signaling via the T4BSS to promote intracellular survival. In this study, we analyzed C. burnetii-mediated temporal modulation of NF- $\kappa \mathrm{B}$ activation/signaling throughout the infectious cycle. We also identified the NF- $\mathrm{B}$ signaling pathway that is activated/modulated during C. burnetii infection. In addition, we analyzed the effect of inhibiting NF- $\kappa \mathrm{B}$ activation on C. burnetii growth and development. Finally, using a T4BSS-defective mutant and transient inhibition of bacterial protein synthesis, we investigated whether $C$. burnetii protein(s) activate NF- $\kappa$ B in a T4BSS-dependent manner. 


\section{MATERIALS AND METHODS}

\section{Growth of $C$. burnetii, Tissue Culture, and Infection}

C. burnetii Nine mile phase II strain stocks were cultivated in African green monkey kidney Vero cells (CCL-81; ATCC, Manassas, VA) and purified as previously described (Morgan et al., 2010). The C. burnetii T4BSS $\Delta$ dotA mutant strain (Beare et al., 2012) and C. burnetii T4BSS $\Delta$ dotA mutant complemented strain were generously provided by Dr. Bob Heinzen (NIAID Rocky Mountain Laboratories, Montana) and grown as previously described (Beare et al., 2012). Non-adherent human monocytic leukemia derived THP-1 cells (TIB-202; ATCC) were grown in $75-\mathrm{cm}^{2}$ tissue culture flasks in RPMI 1640 medium (Gibco, Carlsbad, CA) supplemented with $1 \mathrm{mM}$ sodium pyruvate, and $10 \%$ fetal bovine serum (FBS) at $37^{\circ} \mathrm{C}$ in 5\% CO2 (Mahapatra et al., 2010). Hela 229 epithelial cells (CCL1.2; ATCC) were grown in RPMI 1640 supplemented with $10 \%$ FBS and gentamicin (Invitrogen) at $37^{\circ} \mathrm{C}$ in $5 \% \mathrm{CO}_{2}$ and $95 \%$ humidified air. Infections of THP-1 cells with C. burnetii NMII were initiated in 24-well tissue culture plates at a multiplicity of infection (MOI) of 25. Bacteria were added to $2 \times 10^{6}$ THP- 1 cells per well and incubated at $37^{\circ} \mathrm{C}$ for $4 \mathrm{~h}$ to allow close host cell-bacteria contact. Fresh media was then added to each well for a final concentration of $10^{6}$ cells $/ \mathrm{ml}$. This time point represents $T$ $=0$ for infectious studies.

\section{NF-кB Modulation Assay}

To assay C. burnetii modulation of NF- $\mathrm{KB}$ activation, uninfected or C. burnetii-infected THP-1 cells were incubated for $72 \mathrm{hpi}$. Cells were then incubated in media with $(+)$ or without $(-)$ bacteriostatic levels $(10 \mu \mathrm{g} / \mathrm{ml})$ of $\mathrm{Cm}$ for an additional $24 \mathrm{~h}$ (Mahapatra et al., 2010). Total protein lysates were collected from cell pellets using laemmli sample buffer (Bio-Rad, Hercules, CA) containing protease and phosphatase inhibitor cocktails (Sigma). An NF- $\kappa$ B activation control was generated by treating uninfected THP- 1 cells with $50 \mathrm{ng} / \mathrm{ml}$ of recombinant human TNF- $\alpha$ (R\&D systems) for $8 \mathrm{~h}$ prior to total cellular protein collection (Voth et al., 2007). For temporal analysis, protein lysates from paired infected and uninfected THP- 1 cells were collected at $0,24,48,72,96$, and $120 \mathrm{hpi}$, with one experimental set transiently treated with $10 \mu \mathrm{g} / \mathrm{ml}$ of $\mathrm{Cm}$ for the final 24 $\mathrm{h}$ while the other set was mock-treated. Cell culture media was exchanged daily using centrifugation to harvest the cells and removal of the spent media followed by suspension of the cells in fresh media $\pm \mathrm{Cm}$. Infected and uninfected cells were handled identically and a minimum of three experiments $(N=$ 3 ) were carried out for each time point and condition. Temporal analysis of infected and uninfected differentiated THP-1 cells treated with Rifampin to inhibit mRNA synthesis was performed by treating cells with phorbol 12-myristate 13-acetate (PMA; 200 nM; EMD Biosciences, San Diego, CA) overnight. Cells were infected with C. burnetii, and Rifampin $(10 \mu \mathrm{g} / \mathrm{ml})$ was added $(+$ Rif) or not ( - Rif) at the time of infection. Total protein lysates were collected at 2, 24, 48, 72, and $96 \mathrm{hpi}$ for immunoblot analysis as described below.

\section{RelA Inhibition}

An inhibitory peptide (IP)-DRQIKIWFQNRRMKWKKNGLL SGDEDFSS (Novus Biologicals) - that competitively inhibits phosphorylation of RelA (S529/S536) and a custom synthesized control peptide (CP) - RMDRKWKQIFQNKIWRKSSDELLN DFGGD (Thermofisher scientific)-were used to determine if inhibition of NF-kB activation alters C. burnetii survival/growth in host cells. Initially, the IP's ability to suppress NF- $\mathrm{BB}$ activation in uninfected THP-1 cells was determined. Briefly, $150 \mu \mathrm{m}$ IP or CP was added to $10^{6}$ THP- 1 cells and incubated at $37^{\circ} \mathrm{C}$, $5 \% \mathrm{CO}_{2}$ for $4 \mathrm{~h}$. Recombinant human TNF- $\alpha$ (200 ng/ml; R\&D systems) was then added to induce NF- $\kappa$ B activation. Controls included untreated THP- 1 cells, TNF- $\alpha$ only treated cells, IP only treated cells, and CP only treated cells. After an additional $12 \mathrm{~h}$ incubation, cells were pelleted and total protein lysates collected. After confirmation via immunoblotting that the IP does inhibit NF- $\mathrm{KB}$ activation, it was used to determine the requirement of NF- $\kappa \mathrm{B}$ activation for $C$. burnetii survival/growth. Briefly, $10^{6}$ THP- 1 cells treated with either $10 \mu \mathrm{g} / \mathrm{ml}$ of $\mathrm{Cm}$ (Sigma), $200 \mathrm{ng} / \mathrm{ml}$ of TNF- $\alpha$ (R\&D systems), or IP $(150 \mu \mathrm{m})$ were inoculated with purified C. burnetii NMII at an MOI of 25 . Prior to inoculation, cells were treated with IP for $4 \mathrm{~h}$ or TNF$\alpha$ for $1 \mathrm{~h}$. To ensure consistent cellular response, fresh TNF- $\alpha$ was added every $12 \mathrm{~h}$ and IP every $24 \mathrm{~h}$, respectively. At $72 \mathrm{hpi}$, cells were harvested for (i) total protein lysates, (ii) IFA after cytospin as previously described (Mahapatra et al., 2010) to detect PV formation, or (iii) C. burnetii infectious unit enumeration by sonication lysis of infected cells, serial dilution, and infection of HeLa cell monolayers followed by Fluorescent Forming Unit (FFU) calculation as described (Coleman et al., 2004; Omsland et al., 2009). Briefly, IFA was used to visualize infected cells using a Nikon Eclipse TE 2000-S fluorescence microscope. Fifteen randomly chosen fields of view (FOV) visualized at 20x magnification were counted per well to determine the average number of PVs per FOV. For FFU/ml determination, the FOV average times the area FOV/well and inoculum volume (100 ul) were multiplied by the dilution factor to determine infectious particles from each sample treatment.

\section{Immunoblot Blot Analysis}

Cell lysates were separated by $12 \%$ SDS-PAGE and transferred to a nitrocellulose membrane (Pierce, Rockford, IL). The membranes were blocked for $1 \mathrm{~h}$ at room temperature with 5\% nonfat milk in Tris-buffered saline $(150 \mathrm{mM} \mathrm{NaCl}, 100 \mathrm{mM}$ Tris$\mathrm{HCl}, \mathrm{pH}$ 7.6) containing $0.1 \%$ Tween-20 (TBST) (Voth et al., 2007). Following blocking, membranes were incubated overnight at $4{ }^{\circ} \mathrm{C}$ with $5 \%$ nonfat milk in TBST having primary antibodies for the various target proteins (see following). Detection of NF- $\kappa \mathrm{B}$ was performed using a rabbit monoclonal anti-human primary antibody specific to the phosphorylated Serine 536 form of RelA (Cell Signaling Technology, Danvers, MA). Activation of the non-canonical NF-kB pathway was assayed using rabbit anti-human polyclonal antibody against p100 (the precursor), and p52 (active form of NF-kappaB2, Cell Signaling Technology, Danvers, MA). Determination of C. burnetii density within infected THP-1 cell lysates was performed using rabbit polyclonal antibody against the C. burnetii $27-\mathrm{kDa}$ outer membrane protein 
Com1 as previously described (Morgan et al., 2010). Mouse monoclonal antibodies directed against human $\beta$-actin (Sigma, Saint Louis, MO) were employed as a loading control. After primary antibody incubation, the membranes were washed $3 \mathrm{X}$ with TBST then incubated with either anti-rabbit or anti-mouse IgG secondary antibody conjugated to horseradish peroxidase (KPL, Gaithersburg, MD) for $1 \mathrm{~h}$ at room temperature, washed $3 \mathrm{X}$ in TBST and detected by chemiluminescense following the manufacturer's directions (ECL SuperSignal West Pico Chemiluminescent Substrate, Pierce, Rockford, IL). Visualization and digital imaging of immunoblots was performed on a FluorChem HD2 Imaging System (Alpha Innotech Corporation, Leandro, CA).

\section{Densitometry}

The signal density of the detected bands in experimental samples were analyzed by ImageJ (version $1.46 \mathrm{~h}$ ) as described previously (Schneider et al., 2012). Briefly, relative phosphorylated RelA band intensity was normalized to $\beta$-actin and quantified with respect to uninfected THP-1 cells (Figure 1A) and C. burnetii infected THP-1 cells at 24 hpi (Figure 2A). To examine the role of non-canonical NF- $\kappa$ B signaling pathway, relative NF-кB p100

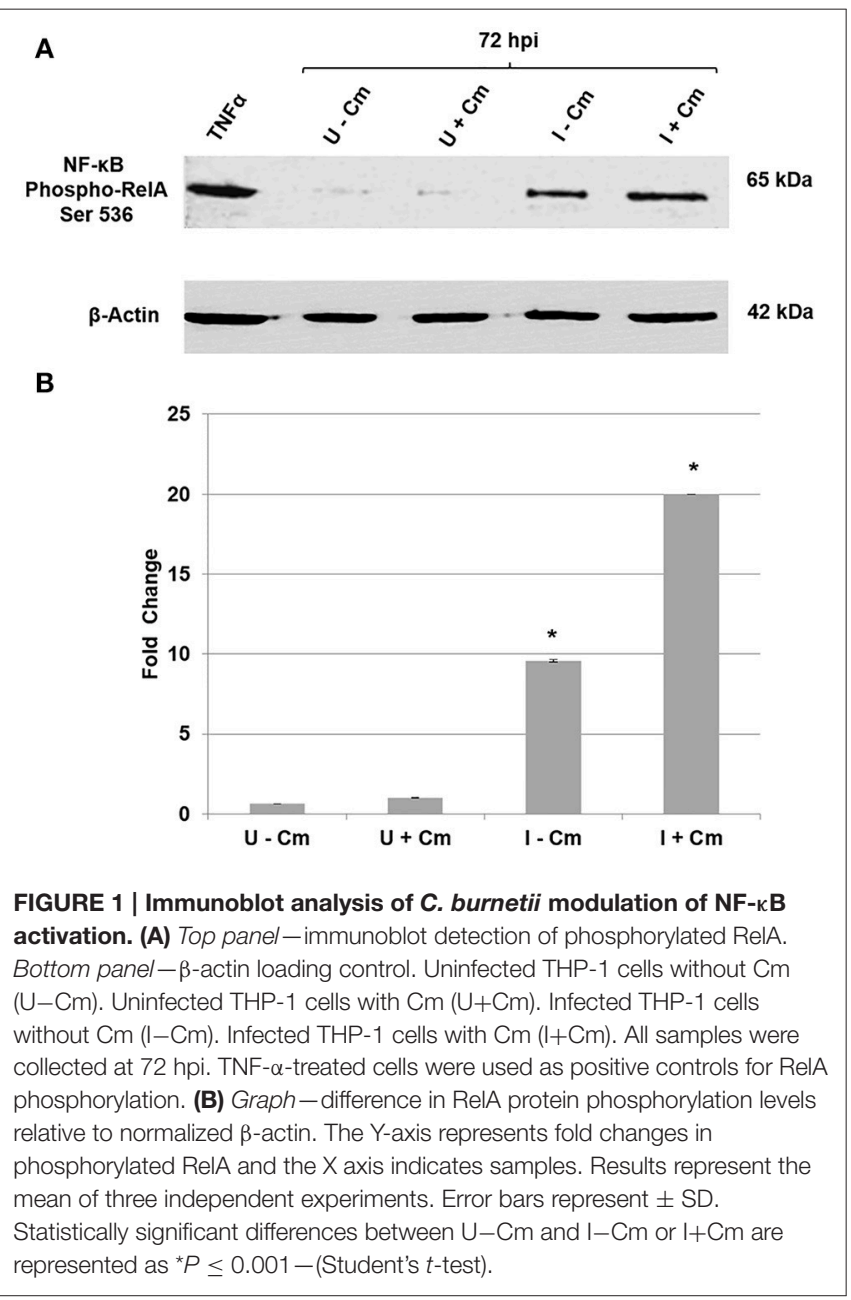

and NF-кB p52 band intensity was normalized to $\beta$-actin and quantified with respect to $C$. burnetii infected THP-1 cells at 24 hpi (Figure 3). In Figure 4D, relative C. burnetii Com 1 band intensity was normalized to $\beta$-actin and quantified with respect to C. burnetii infected THP-1 cells at 72 hpi. For Figure 5A, relative phosphorylated RelA band intensity was normalized to $\beta$-actin and quantified with respect to uninfected THP-1 cells.

\section{Immunofluorescent Microscopy}

An indirect immunofluorescence assay (IFA) was used to enumerate PV and infectious C. burnetii. For immuno-staining, methanol-fixed C. burnetii-infected cells were incubated $1 \mathrm{~h}$ with polyclonal Guinea pig anti-C. burnetii primary sera diluted in PBS, 2\% BSA. After 3 PBS washes, samples were incubated $1 \mathrm{~h}$ with Alexa488-conjugated goat anti-Guinea pig secondary IgG (Molecular probes, Thermo Fisher) also diluted in PBS, 2\% BSA. DAPI (4',6-diamidino-2-phenylindole) was used in the secondary incubation to stain total DNA. Labeled cells were visualized using a Nikon Eclipse TE 2000-S fluorescence microscope with a Nikon DS FI1 camera and NIS-ELEMENTS F 3.00 software (Mahapatra et al., 2010). A minimum of 15 fields per sample were counted using the 20x objective. All experiments were performed with 3 biological samples and statistical analyses were performed using a paired Student's $t$-test.

\section{Transfections and GFP-RelA/DAPI Co-localization Assay}

Hela cells were transiently transfected with the GFP-RelA plasmid (Addgene) using X-tremeGENE 9 DNA Transfection Reagent (Roche Life Sciences), as described by the manufacturer. Transfected cells were grown overnight and then inoculated with either C. burnetii NMII, C. burnetii $\Delta \operatorname{dotA}$ (Beare et al., 2012), or a C. burnetii $\operatorname{dot} A$-complemented strain (Beare et al., 2012). Separate cells were also infected with C. burnetii NMII concurrent with the addition of Cm (Mahapatra et al., 2010). C. burnetii $\triangle \operatorname{dot} A$ strain and $\operatorname{dot} A$-complemented strains were generously provided by Dr. Robert A. Heinzen (Rocky Mountain Laboratories, NIAID, NIH, Hamilton, MT) (Beare et al., 2012). All strains were used at an MOI of 25. At 24 and 48 hpi, cells were methanol-fixed and IFA performed as above using Guinea pig anti-C. burnetii primary antibody and Alexa555-conjugated goat anti-Guinea pig secondary IgG (Molecular probes, Thermo Fisher). DAPI was used to stain total DNA. Subcellular colocalization of GFP-RelA and DAPI in transfected cells was visualized as above using a 60x oil objective. A minimum of 100 transfected cells were scored per sample. Data shown are the means of three independent experiments and statistical analyses were performed using a paired Student's $t$-test.

\section{RESULTS}

\section{NF- $\kappa B$ Activation is Modulated by C. burnetii Proteins during Infection}

RelA is one of the most extensively studied NF- $\kappa$ B complex subunits (Sakurai et al., 2003; Bonizzi and Karin, 2004; Perkins, 2007). Similar to cRel and RelB, it contains a 300-amino acid region with homology to the $\mathrm{Rel}$ proto-oncogene ( $\mathrm{RH}$ domain) 


\section{A}
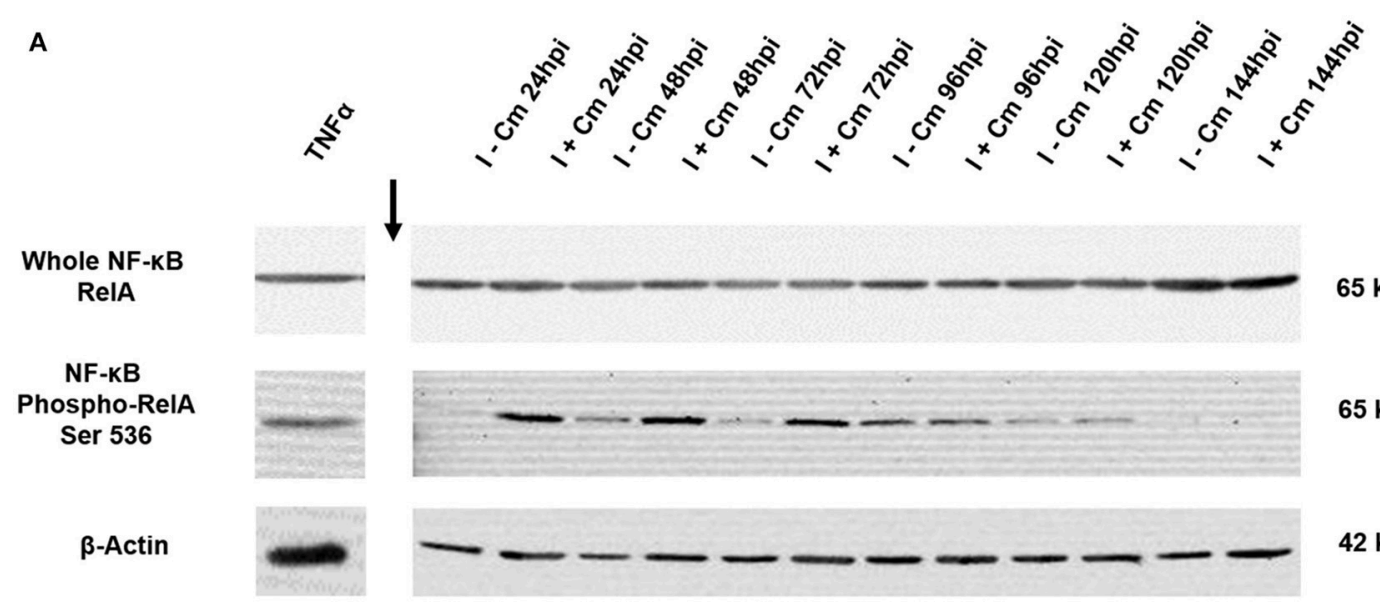

$65 \mathrm{kDa}$

$65 \mathrm{kDa}$

B

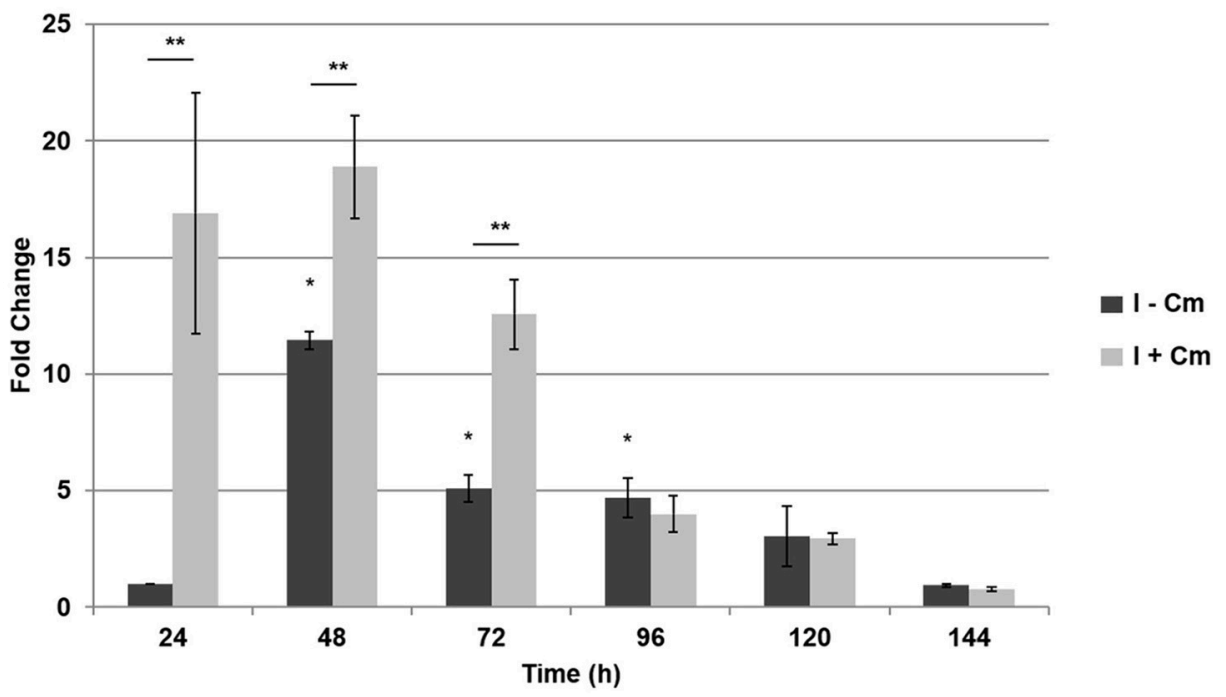

C

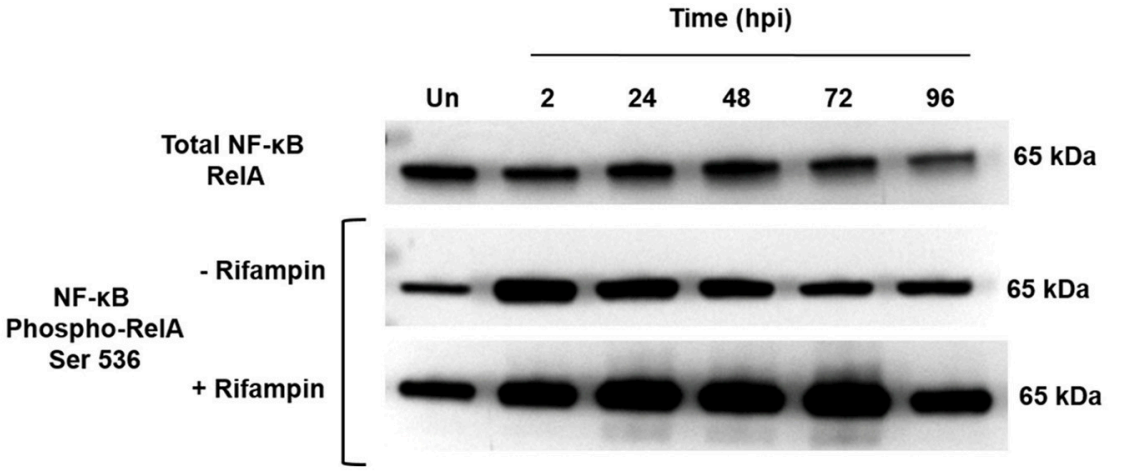

FIGURE 2 | Temporal analysis of NF-kB activation in C. burnetii-infected THP-1 cells. (A) Representative immunoblots showing NF-kB activation and controls over a time course of $C$ burnetii infection. Top panel-RelA probed with a monoclonal antibody. Middle panel-phosphorylated RelA probed with a monoclonal antibody against S536. Bottom panel- $\beta$-actin loading control. Time (hpi) at which untreated (I-Cm) and $\mathrm{Cm}$-treated (I+Cm) C. burnetii-infected THP-1 cells were harvested is indicated above lanes. Arrow indicates lane break. (B) Fold change of phosphorylated RelA vs. time in the presence and absence of Cm. Results of densitometric analysis are presented as the mean of three experiments. Error bars show \pm S.E.M. Statistical differences were calculated using a $t$-test for paired samples. * Signifies $P<0.05$ of $\mathrm{I}-\mathrm{Cm}$ samples compared to $24 \mathrm{hpi}$. ${ }^{*}$ Signifies $P<0.05$ between paired $(\mathrm{I}-\mathrm{Cm}$ to $\mathrm{I}+\mathrm{Cm})$ samples at each time point. (C) A representative immunoblot showing phosphorylated RelA levels in PMA-differentiated THP-1 cells treated or mock-treated with Rifampin 2-96 hpi. Top panel-RelA control probed with a monoclonal antibody. Middle panel-phosphorylated RelA from infected cells mock-treated with Rifampin (-Rifampin). Bottom panel-phosphorylated RelA from infected cells treated with Rifampin (+Rifampin). Time (hpi) at which cells were harvested is indicated above each lane. Un $=$ Uninfected cells. 


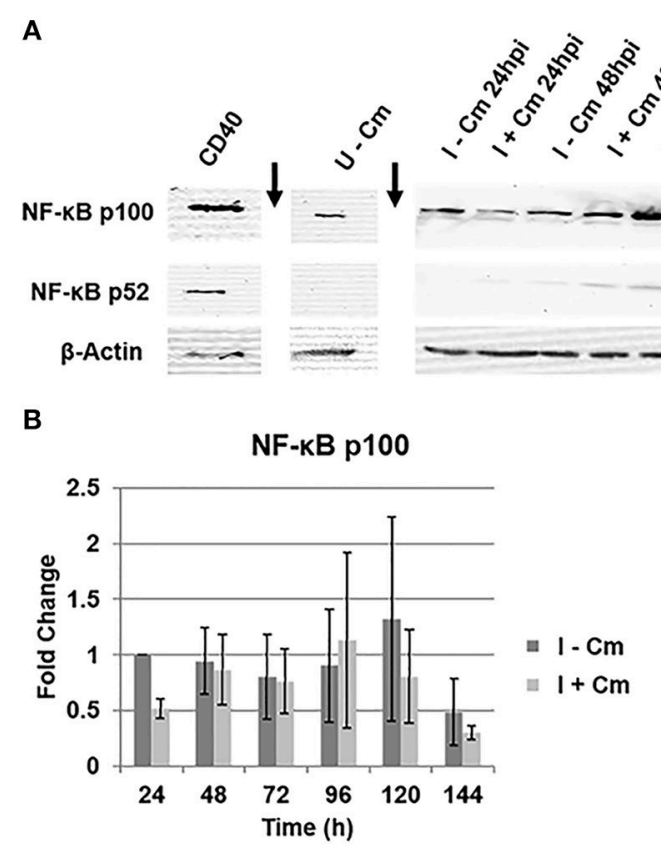

C

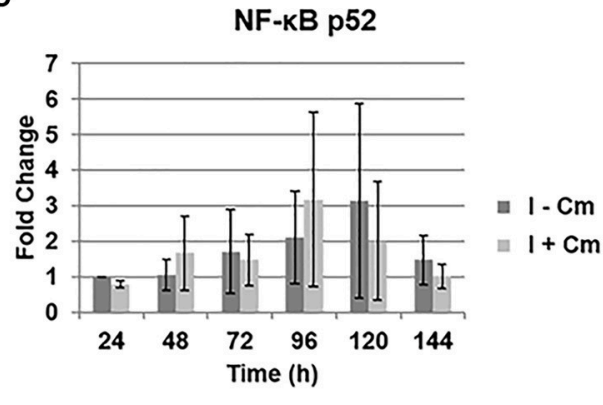

FIGURE 3 | Immunoblot analysis of NF-кB p100 and p52 in C. burnetii-infected cells. (A) Representative immunoblots showing NF-кB p100 and p52 in C. burnetii-infected THP-1 cells either treated with $\mathrm{Cm}(\mathrm{I}+\mathrm{Cm})$ or left untreated $(\mathrm{I}-\mathrm{Cm})$. Blots were probed with a polyclonal rabbit antibody against NF-kB (p100/p52) of human origin (Top/Middle panels, respectively). Bottom panel- $\beta$-actin loading control. CD40-treated THP-1 cells served as a p52 positive control. Sample conditions and time point are indicated above each lane. Arrows indicate lane breaks. (B) Results of densitometric analysis showing fold changes of NF-kB p100 levels over time of infection with and without $\mathrm{Cm}$ after $\beta$-actin normalization. Error bars show \pm S.E.M of three biological experiments. (C) Fold changes of NFKB p52 levels over time of infection with and without $\mathrm{Cm}$ after $\beta$-actin normalization. Error bars show \pm S.E.M of three biological experiments.

and a transactivation domain (Sakurai et al., 2003; Bonizzi and Karin, 2004; Perkins, 2007). The RH domain harbors motifs for nuclear localization and binding to specific DNA sequences, while the transactivation domain contains phosphorylation sites that remain bound to the inhibitor IкB while in the cytoplasm (Sakurai et al., 2003; Bonizzi and Karin, 2004; Perkins, 2007). Phosphorylation of serine 536 (S536) in the transactivation domain is required for optimal activation (Sakurai et al., 2003; Bonizzi and Karin, 2004; Viatour et al., 2005; Perkins, 2007). To determine if NF- $\kappa \mathrm{B}$ is modulated by C. burnetii, NF- $\mathrm{\kappa B}$ activation was assayed in THP- 1 cells via detection of RelA phosphorylation during infection and treatment with Cm (Sakurai et al., 2003). Figures 1A,B reveal that NF- $\kappa B$ is activated during infection as evidenced by increased levels of phosphorylated RelA, and that C. burnetii protein synthesis is required to modulate the level of activation. Compared to uninfected cells, RelA phosphorylated protein levels increased $\sim 10$-fold in C. burnetii-infected cells. However, phosphorylated RelA levels were $\sim 20$-fold higher in infected cells treated with $\mathrm{Cm}$. These results indicate that C. burnetii proteins modulate NF- $\mathrm{kB}$ signaling during infection.

\section{C. burnetii Modulates NF-кB Activation Temporally during Infection}

To assess the dynamics of NF- $\kappa B$ activation throughout infection, we examined infected THP-1 cells from 24-144 hpi. Cells were either mock-treated or transiently treated with $\mathrm{Cm}$. We hypothesized that NF-KB activation would respond directly to de novo bacterial protein synthesis depending on the stage of infection (early [24-48 hpi], mid [48-96 hpi], or late [96-144 hpi]). To test this hypothesis, we first investigated the total levels of RelA. As shown in Figure 2A, RelA levels at each time post-infection were consistent throughout infection, indicating C. burnetii does not modulate the relative expression of RelA. We next assessed RelA phosphorylation in the presence and absence of transient $\mathrm{Cm}$ treatment. Figures 2A,B show that in the absence of transient $\mathrm{Cm}$ treatment, phosphorylated RelA levels remain low at 24 hpi (early infection). However, when compared to $24 \mathrm{hpi}$, RelA phosphorylation levels significantly increase at 48 hpi (early to mid-infection) and remain elevated through 96 hpi (mid infection). Notably, transient application of $\mathrm{Cm}$ at 0,24 , and $48 \mathrm{hpi}$ resulted in even higher levels of phosphorylated RelA at 24,48 , and $72 \mathrm{hpi}$, respectively, suggesting that $C$. burnetii proteins dampen NF- $\mathrm{kB}$ activation during infection. Interestingly, application of $\mathrm{Cm}$ at $72 \mathrm{hpi}$ did not alter RelA phosphorylation levels at 96 hpi relative to infected cells in the absence of $\mathrm{Cm}$. During late infection times (96-144 h), RelA phosphorylation was reduced and de novo C. burnetii protein synthesis did not alter NF-кB activation. Combined, these results indicate that infection of THP- 1 cells by $C$. burnetii involves temporal modulation of NF- $\mathrm{KB}$ activation via RelA phosphorylation. While C. burnetii infection triggers NF-кB activation, de novo C. burnetii proteins significantly suppress NF- $\mathrm{KB}$ activation during early and middle stages of 


\section{A}
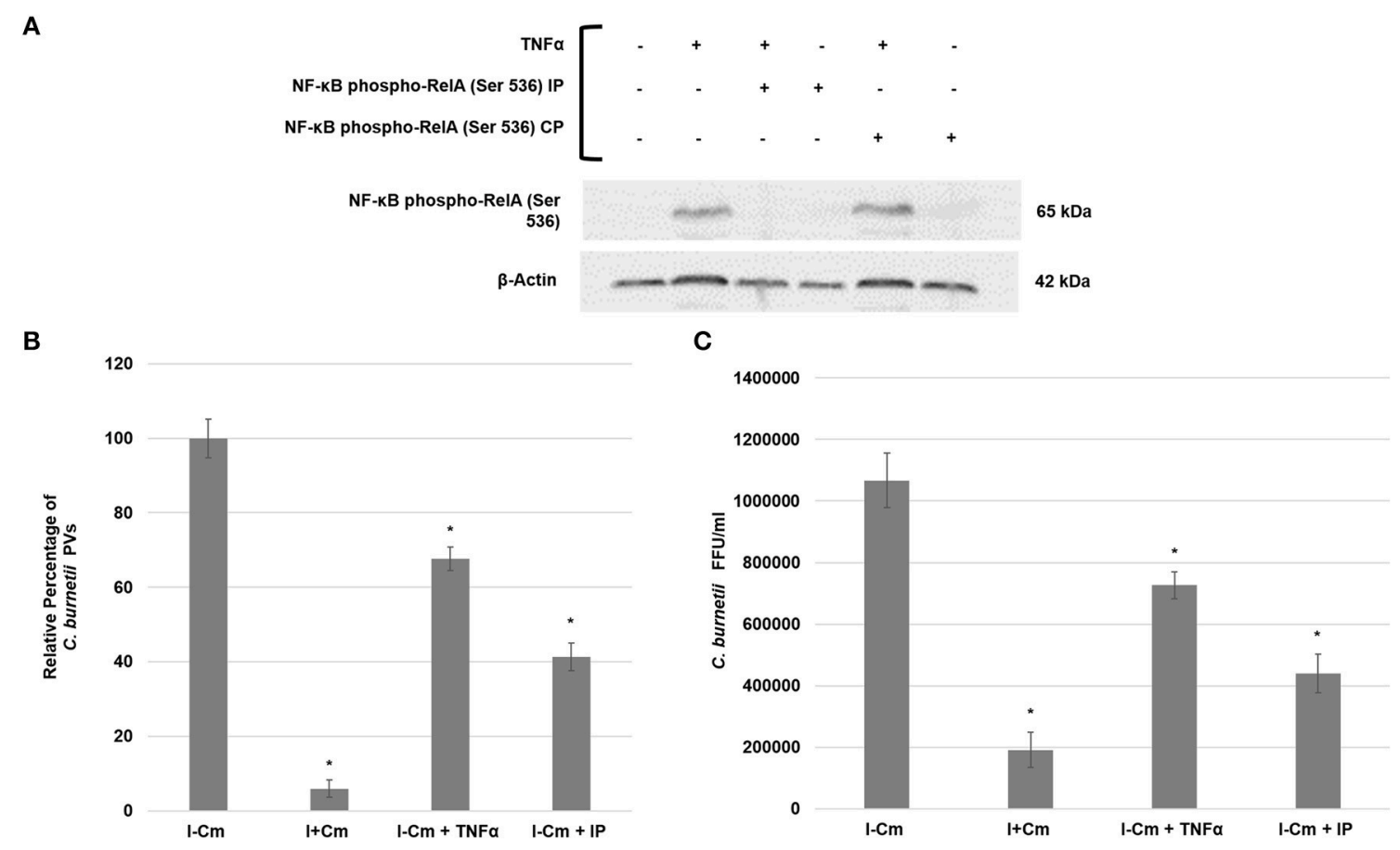

D

$\mathbf{E}$
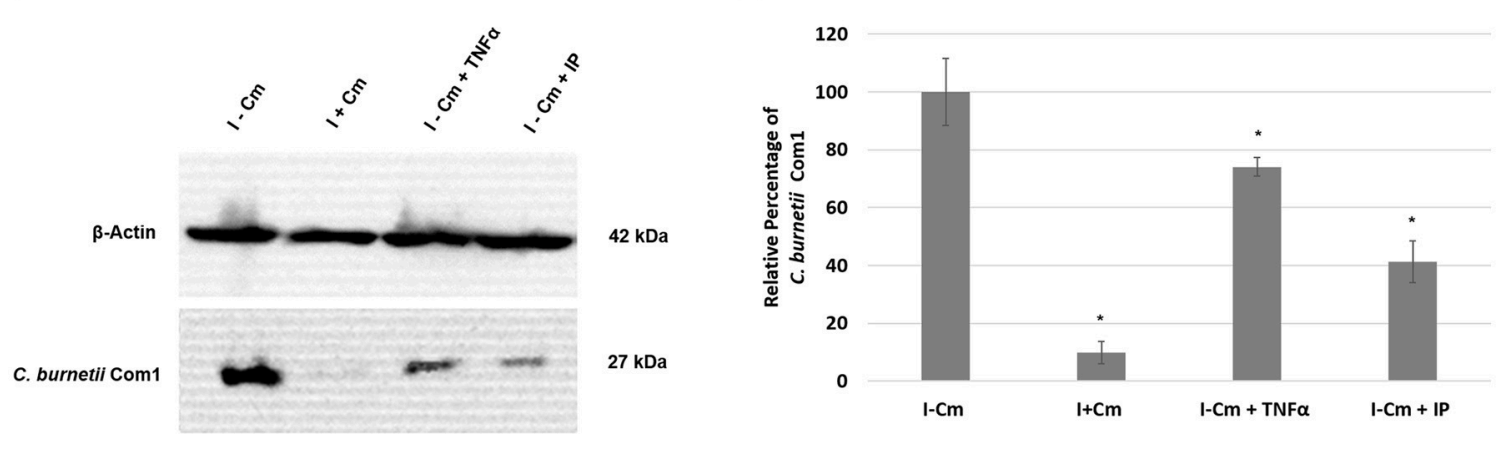

FIGURE 4 | C. burnetii development following NF-кB activation or inhibition. (A) Top pane/-immunoblot detection of phosphorylated RelA in THP-1 cells. Bottom panel $-\beta$-actin loading control. Sample treatments $( \pm)$ are indicated above immunoblot panels and correlate to the lanes below. (B) Inhibition of RelA phosphorylation in THP-1 cells impairs C. burnetii PV formation. 15 fields of view at 20x magnification (>100 cells/field of view) from three independent samples were analyzed for PV enumeration. Error bars show \pm S.E.M. Statistical differences relative to $\mathrm{I}-\mathrm{Cm}$ were calculated using a $t$-test for paired samples (*signifies $P<0.05$ ). (C) Infectious progeny enumeration in Hela cells from three independent samples as measured by IFA and Fluorescent Forming Units (FFUs). Error bars show \pm SEM. Statistical differences relative to $\mathrm{I}-\mathrm{Cm}$ were calculated using a $t$-test for paired samples (*signifies $P<0.05$ ). (D) Representative immunoblot showing Com1 levels in C. burnetii-infected THP-1 cells either untreated or treated with $\mathrm{Cm}$, TNF- $\alpha$, or RelA IP and harvested at 72 hpi. Top panel- $\beta$-actin control. Bottom panel-Com1 detected with a rabbit polyclonal antibody. (E) Differences in C. burnetii Com1 levels relative to normalized $\beta$-actin from three independent samples were analyzed. All samples were analyzed at 72 hpi. C. burnetii growth was examined in THP-1 cells either untreated $(I-C m)$, or treated with $\mathrm{Cm}(\mathrm{I}+\mathrm{Cm})$, TNF- $\alpha$, or RelA IP. Error bars represent \pm SEM. Statistically significant differences relative to $\mathrm{I}-\mathrm{Cm}$ are represented as ${ }^{*} P \leq 0.05$, (Student's $t$-test).

intracellular growth. To confirm these findings, we examined the effect of treatment with the mRNA synthesis inhibitor rifampin on temporal NF-kB activation during infection. Additionally, to determine if these observations were infection model-specific, we assessed infection of PMA-differentiated THP-1 macrophagelike cells. Cells were treated with rifampin at the time of infection, and RelA phosphorylation assessed at 2, 24, 48, 72, and 96 hpi. Figure 2C shows that RelA phosphorylation levels in differentiated THP-1 cells infected with C. burnetii increased relative to uninfected cells. Furthermore, inhibition of bacterial mRNA synthesis resulted in even higher levels of RelA phosphorylation that were evident through $96 \mathrm{hpi}$ similar to Figure 2A. These observations support our findings that indicate C. burnetii proteins temporally modulate NF-кB activation during infection.

\section{C. burnetii Does Not Modulate NF-кB Activation via the Non-canonical Pathway}

The results above demonstrate the involvement of RelA in NF- $\mathrm{KB}$ activation. NF- $\mathrm{KB}$ transcription factors are typically activated by 
either the canonical or non-canonical signaling pathway (Beinke and Ley, 2004; Bonizzi and Karin, 2004; Park et al., 2005; Viatour et al., 2005; Perkins, 2007). The canonical pathway transmits signals via RelA activation, while the non-canonical pathway functions through NF-кB p52 activation (Beinke and Ley, 2004; Bonizzi and Karin, 2004; Park et al., 2005; Viatour et al., 2005; Perkins, 2007). Formation of active p52 occurs via proteolytic processing of the p100 precursor (Beinke and Ley, 2004; Bonizzi and Karin, 2004; Park et al., 2005; Viatour et al., 2005; Perkins, 2007). Therefore, to determine if the non-canonical pathway is activated during C. burnetii infection of THP-1 cells, we used immunoblot analysis to detect NF- $\kappa$ B p100/p52. Figure 3 clearly demonstrates that $C$. burnetii does not modulate host cell NF-KB p100 and p52 levels over the course of infection (24-144 hpi) in the presence or absence of bacterial protein synthesis. When compared to C. burnetii-infected cells at $24 \mathrm{hpi}$, NF- $\mathrm{kB}$ p100 levels remain constant throughout infection, and addition of $\mathrm{Cm}$ does not significantly impact p100 expression (Figure 3B). In contrast, p52 levels are barely detectable and do not significantly change in the presence or absence of $\mathrm{Cm}$ (Figure 3C). Together, these data reveal that NF- $\mathrm{KB}$ activation in infected THP-1 cells does not involve non-canonical NF- $\kappa$ B signaling.

\section{Inhibition of NF-кB Activation Impairs C. burnetii Development}

To determine if C. burnetii-mediated NF- $\mathrm{KB}$ activation is essential for intracellular survival and growth, we treated THP1 cells with an inhibitory peptide (IP) that competitively inhibits RelA (S529/S536) phosphorylation to suppress NF-KB activation. Inhibition of RelA phosphorylation was confirmed by immunoblotting using TNF- $\alpha$ to trigger RelA phosphorylation (Figure 4A). Figure 4A demonstrates the effectiveness of TNF $\alpha$ to induce RelA phosphorylation and the IP's ability to inhibit RelA phosphorylation. To measure C. burnetii development following induction (TNF $\alpha$ ) or inhibition (IP) of NF- $\mathrm{KB}$ activation, we analyzed (i), the number of treated THP-1 cells with PV relative to infected, untreated cells, (ii) the number of infectious progeny produced in Hela cells by treated THP1 cell lysates relative to infected, untreated THP-1 cell lysates, and (iii) levels of the major outer membrane protein Com1 in treated and untreated THP-1 cells as a measure of C. burnetii total protein. Figures 4B-D show that PV formation, infectious progeny, and C. burnetii Com1 levels were reduced by approximately $20-30 \%$ in THP- 1 cells pretreated with TNF$\alpha$. Of particular interest, Figure 4B demonstrates that, compared to $C$. burnetii infected cells, PV are reduced by approximately $60 \%$ in IP-treated cells. Figures 4C-E confirm and support these observations, demonstrating that the number of infectious C. burnetii produced (Figure 4C) within IP-treated cells as well as the amount of Com1 detected in these cells (Figures 4D,E) was reduced by approximately $60 \%$. Collectively, these results demonstrate that C. burnetii development is significantly impaired when NF- $\kappa B$ activation is inhibited. Additionally, unlike $\mathrm{Cm}$ treatment, $C$. burnetii is able to overcome high levels of activated NF- $\kappa$ B induced by TNF- $\alpha$ application. However, their growth is marginally inhibited.

\section{C. burnetii Requires a Functional Dot/lcm T4BSS to Modulate NF- $к B$ Signaling}

Pathogenic microorganisms employ unique strategies to interfere with NF- $\kappa B$ signaling (Rahman and McFadden, 2011). Bacteria modulate NF- $\mathrm{kB}$ signaling (activation or suppression) depending on requirements of their intracellular lifestyle and niche (Rahman and McFadden, 2011). C. burnetii's close relative, L. pneumophila, utilizes over $10 \mathrm{Dot} / \mathrm{Icm}$ effectors to induce a biphasic pattern of NF- $\kappa$ B activation (Rahman and McFadden, 2011; Shin, 2012). To determine if the C. burnetii T4BSS plays a role in modulating NF$\kappa \mathrm{B}$, we analyzed RelA phosphorylation in THP-1 cells infected with either wild type $C$. burnetii $( \pm \mathrm{Cm})$, a $C$. burnetii T4BSS $\triangle \operatorname{dot} A$ mutant, or a $\operatorname{dot} A$-complemented strain. Figures 5A,B reveal that, compared to cells infected with wild type C. burnetii (I-Cm), levels of phosphorylated RelA were higher in cells infected with C. burnetii $(\mathrm{I}+\mathrm{Cm})$ or the $\Delta \operatorname{dot} A$ mutant. However, levels of phosphorylated RelA were similar in cells infected with either wild type C. burnetii $(-\mathrm{Cm})$ or the $\triangle \operatorname{dot} A$ complemented strain. Together, these results suggest that $C$. burnetii protein synthesis and a functional T4BSS are required for NF- $\mathrm{KB}$ modulation. To confirm this observation and determine if this event extends to RelA nuclear translocation, we transiently transfected Hela cells with GFP-RelA and examined nuclear translocation when infecting cells with either wild type C. burnetii $( \pm \mathrm{Cm})$, the $\Delta \operatorname{dot} A$ mutant, or the $\Delta \operatorname{dot} A$-complemented strain. Migration of GFP-RelA into the nucleus indicates NF- $\mathrm{BB}$ activation. Using immunofluorescence microscopy we visualized RelA colocalization with DAPI (DNA stain). Figure S1 and

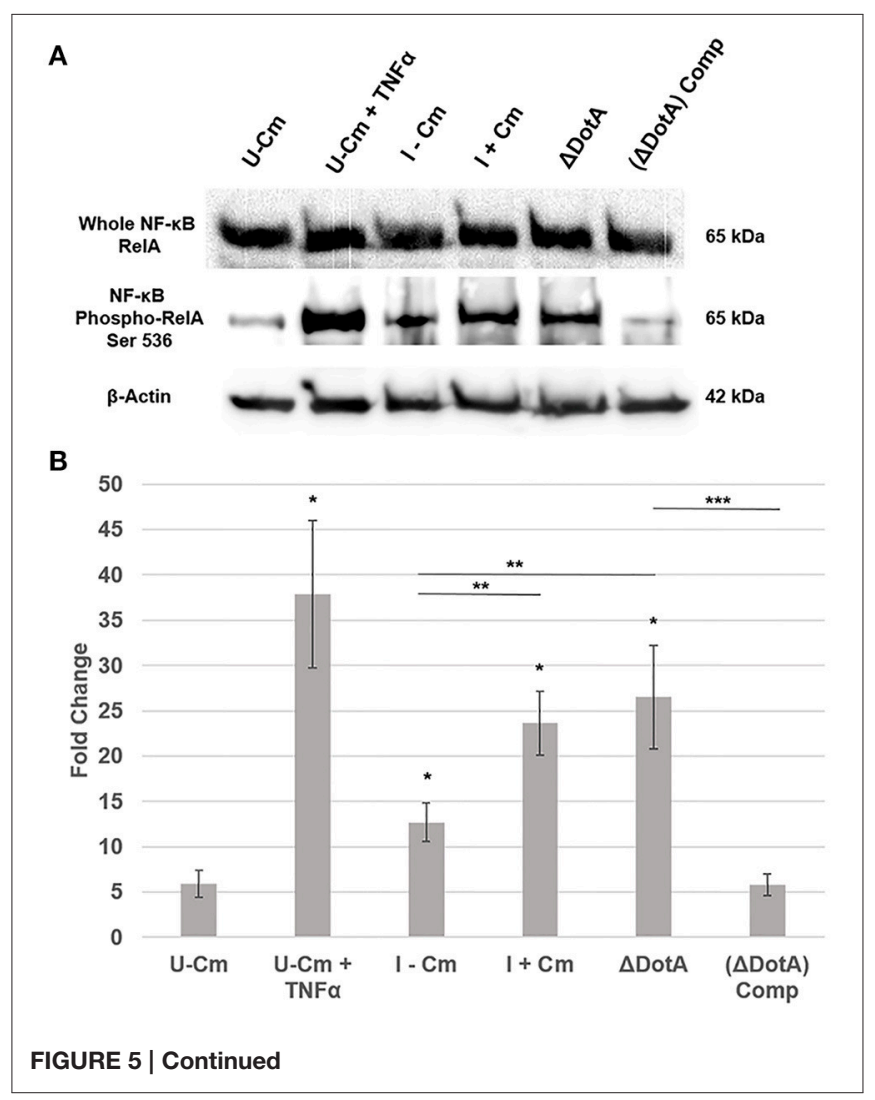




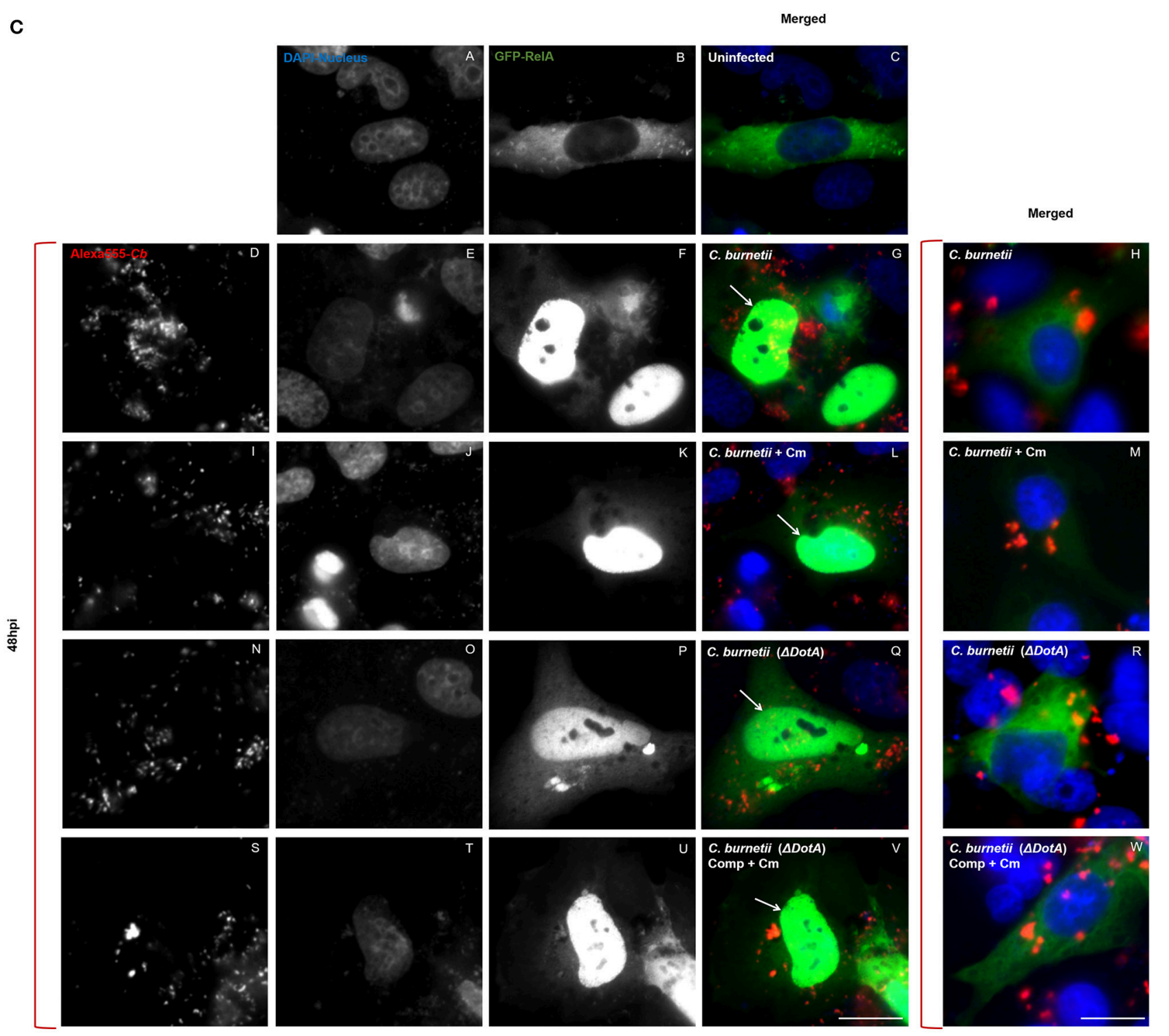

FIGURE 5 | Continued

Figure 5C show that at 24 and 48 hpi, GFP-RelA localized to the nucleus regardless of the $C$. burnetii strain used to infect the cells. However, quantification of the amount of GFP-RelA in the nucleus of infected cells revealed that wild type $C$. burnetii $(+\mathrm{Cm})$ and the $\Delta \operatorname{dot} A$ mutant had approximately $50 \%$ more cells with nuclear-localized GFP-RelA (Figure 5D). These data clearly demonstrate that NF- $\mathrm{B}$ activation levels are significantly higher in infected cells treated with $\mathrm{Cm}$ and cells infected with the $\Delta \operatorname{dot} A$ mutant, suggesting that T4BSS effectors play a crucial role in modulating $\mathrm{NF}-\kappa \mathrm{B}$ signaling.

\section{DISCUSSION}

Manipulation of host NF-кB signaling via secreted effector activity is a strategy used by many microbial pathogens to thwart innate and adaptive immune responses (Rahman and McFadden, 2011). NF- $\kappa$ B activation typically induces the expression of hundreds of genes (Beinke and Ley, 2004; Bonizzi and Karin, 2004; Park et al., 2005; Viatour et al., 2005; Rahman and McFadden, 2006, 2011; Perkins, 2007). Genes targeted by NF- $\kappa \mathrm{B}$ include those encoding pro-inflammatory cytokines, chemokines, and adhesion molecules that regulate recruitment and trafficking of immune cells to the site of infection (Beinke and Ley, 2004; Bonizzi and Karin, 2004; Park et al., 2005; Viatour et al., 2005; Perkins, 2007). NF- $\kappa$ B activation also induces the transcription of genes such as defensins that have direct microbicidal activity, and enzymes that generate reactive intermediates (Beinke and Ley, 2004). NF- $\kappa$ B acts as a major molecular link between the launch of innate and adaptive immunity by facilitating $\mathrm{T}$ cell activation via induction of $\mathrm{MHC}$ 


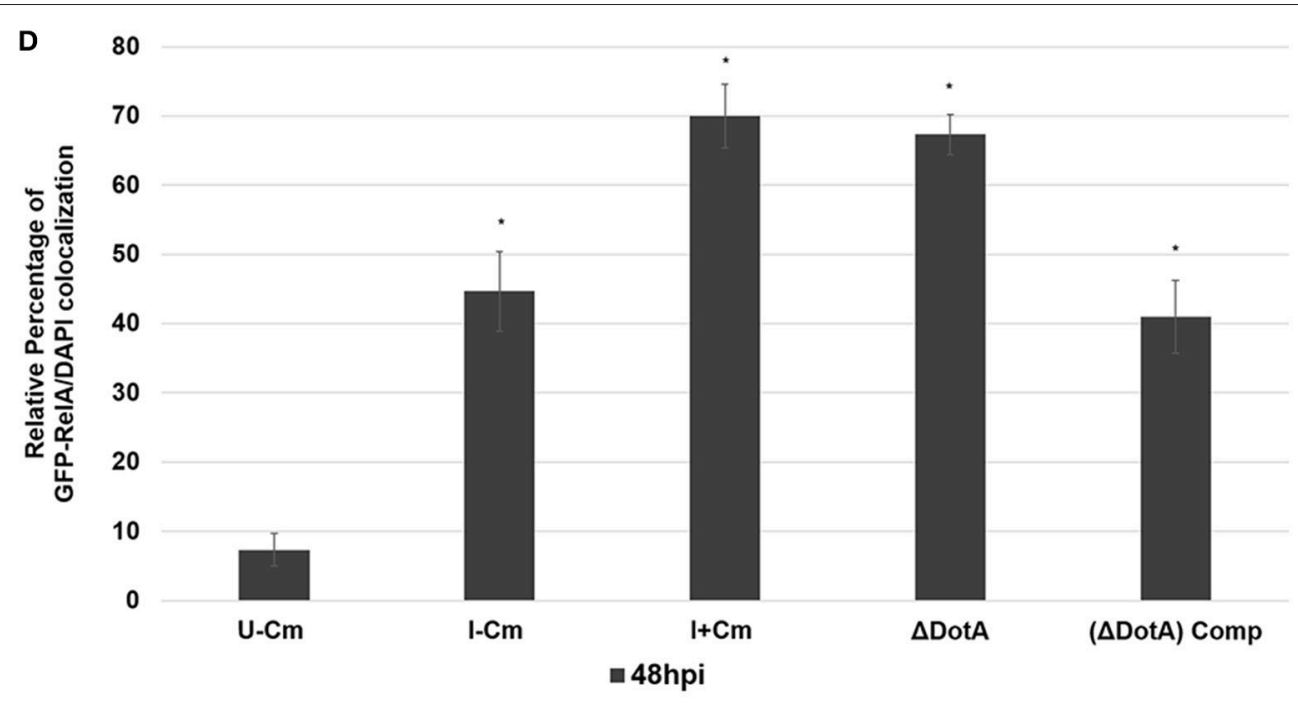

FIGURE 5 | C. burnetii employs the Dot/lcm T4BSS to modulate NF-кB signaling. (A) Immunoblot analysis of NF-кB activation in THP-1 cells (48 hpi) using wild type $C$. burnetii $( \pm \mathrm{Cm})$, a DotA mutant $(\triangle d o t A)$, and a dotA-complemented strain $(\Delta d o t A)$ Comp. Top panel-detection of RelA. Middle panel-detection of phosphorylated RelA. Bottom panel- $\beta$-actin loading control. TNF- $\alpha$-treated cells were used as positive RelA phosphorylation controls. (B) Differences in phosphorylated RelA levels relative to normalized $\beta$-actin. The $Y$-axis represents fold changes in phoshorylated RelA by densitometry and the $X$ axis indicates samples. Results represent the mean of three independent experiments. Error bars represent $\pm \mathrm{SEM}$. For statistically significant differences, ${ }^{*}$ signifies $P<0.05$ when samples are compared to $\mathrm{U}-\mathrm{Cm}$, ${ }^{*}$ signifies $P<0.05$ when samples are compared between $\mathrm{I}-\mathrm{Cm}$ to $\mathrm{I}+\mathrm{Cm}$ or $\Delta$ dotA. ${ }^{* *}$ Signifies $P<0.05$ when samples are compared between $\Delta d$ dotA and $\Delta$ dotA Comp-(Student's $t$-test). (C) Immunofluorescent image showing localization of GFP-RelA (green). C. burnetii was visualized by Alexa-555 (red), and DNA/Nuclei with Dapi (blue). HeLa cells transiently transfected with GFP-RelA (green) vector were infected with the indicated C. burnetii strains for $48 \mathrm{~h}$. (A-C) Uninfected cells. (D-G,I-L,N-Q,S-V) Cells infected with the indicated C. burnetii strain in which GFP-RelA and DAPI co-localize. Arrows indicate co-localization. $(\mathrm{H}, \mathrm{M}, \mathrm{R}, \mathrm{W})$ Merged micrographs representing cells infected with the indicated C. burnetii strain where GFP-RelA did not co-localize with DAPI. Bar, $10 \mu \mathrm{m}$. (D) Quantification of GFP-RelA/DAPI co-localization. A minimum of 100 transiently transfected Hela cells from each of three separate experiments was counted to determine GFP-ReIA/DAPI co-localization. Error bars show \pm SD. Statistically significant differences ( ${ }^{*} P<0.05$, Student's $t$-test) are shown when samples are compared to $\mathrm{U}-\mathrm{Cm}$ at $48 \mathrm{hpi}$.

proteins and CD80/86 in antigen-presenting cells (Beinke and Ley, 2004). B cell differentiation is also usually stimulated by NF- $\kappa \mathrm{B}$ activation (Beinke and Ley, 2004). Additionally, NF- $\kappa \mathrm{B}$ plays a critical role in expression of anti-apoptotic proteins (e.g., c-IAP-1/2, AI/Bfl-1, Bcl-2, and Bcl- $\mathrm{X}_{\mathrm{L}}$ ) (Beinke and Ley, 2004; Rahman and McFadden, 2011). Regulation of the cell-cycle protein cyclin D1, which increases cellular survival and proliferation, is also dependent on NF- $\kappa \mathrm{B}$ activation (Beinke and Ley, 2004; Rahman and McFadden, 2011). Thus, master regulators such as $\mathrm{NF}-\kappa \mathrm{B}$ are prime targets for pathogenic microorganisms that promote survival by "regulating the regulator" to meet the requirements of their intracellular life cycle. In the current study, we demonstrate that C. burnetii modulates host NF- $\mathrm{B}$ during infection in a T4BSS-dependent manner.

We discovered that $C$. burnetii modulates NF- $\kappa \mathrm{B}$ activation through a process that requires de novo bacterial protein and mRNA synthesis (Figures 1, 2). Our findings clearly indicate that C. burnetii promotes NF- $\kappa \mathrm{B}$ activation via RelA phosphorylation in a temporal manner, and bacterial protein and mRNA synthesis inhibitors alter activation. These findings indicate that C. burnetii maintains a balance between activation and suppression of NF$\kappa \mathrm{B}$ signaling during infection. Depending on the stage of infection, bacteria typically either activate or suppress NF-кB signaling (Rahman and McFadden, 2011). Studies on C. burnetii's close phylogenetic relative reveal that L. pneumophila induces a biphasic pattern of NF- $\kappa \mathrm{B}$ activation in human epithelial cells (Bartfeld et al., 2009; Rahman and McFadden, 2011; Shin, 2012). Short term activation at early time of infection $(<8 \mathrm{hpi})$ is followed by decreased activation, which is then followed by long term induction of NF- $\kappa \mathrm{B}$ later in infection (Bartfeld et al., 2009). Unlike L. pneumophila, our data suggest that C. burnetii activates NF- $\kappa \mathrm{B}$ at a low level for at least the first 5 days of a $\sim 6$ day infection cycle (Figure $\mathbf{2 A}$ ). Importantly, activation is suppressed relative to $\mathrm{Cm}$ - and rifampin-treated infections, indicating the response of the host cell is robust NF- $\kappa$ B activation in the absence of ongoing C. burnetii macromolecular synthesis. Activation and suppression of NF-кB signaling during early to mid-infection likely promotes cell survival and prevents a robust immune response.

NF- $\kappa \mathrm{B}$ can be activated by canonical and non-canonical pathways. Our findings indicate that $C$. burnetii does not modulate NF- $\kappa$ B via the non-canonical pathway (Figure 3). This finding is crucial to narrow C. burnetii modulation of NF- $\kappa \mathrm{B}$ activation to canonical pathway molecular components upstream and downstream of RelA. Canonical NF- $\kappa$ B pathway-associated molecular components, such as host inducer ligands, receptors, adaptor molecules, IКB proteins, and kinases, may play a crucial role in C. burnetii-mediated activation or suppression of NF- $\kappa \mathrm{B}$ signaling and are commonly targeted by intracellular bacterial 
pathogens (Rahman and McFadden, 2011). Examples include Shigella flexneri and Yersinia spp. that use the type III secretion system effectors OspG and YopP/J, respectively, to prevent ІкB degradation, maintaining NF- $\kappa \mathrm{B}$ inactive in the cytosol (Bhavsar et al., 2007). Conversely, activation of canonical NF-кB signaling protects several intracellular pathogens including Mycobacterium tuberculosis (Dhiman et al., 2007), Bartonella henselae (Kempf et al., 2005), Chlamydia pneumonia (Wahl et al., 2001), Rickettsia rickettsii (Clifton et al., 1998), and L. pneumophila (Abu-Zant et al., 2007) from cell death. Our results clearly indicate that inhibition of RelA phosphorylation restricts PV formation and reduces infectious progeny production (Figure 4). It is tempting to speculate that in the absence of some level of NF- $\kappa \mathrm{B}$ activation, THP-1 cells prevent $C$. burnetii development by promoting pro-apoptotic mechanisms. It is likely that NF$\kappa \mathrm{B}$-mediated anti-apoptotic genes such as c-iap2 and $a 1 / b f l-1$, which are up-regulated in C. burnetii-infected cells (Voth et al., 2007), would not be expressed when RelA phosphorylation is abrogated. Together, these findings suggest that two opposing effects of NF- $\kappa \mathrm{B}$ activation occur in C. burnetii-infected cells: (1) some level of NF- $\mathrm{B}$ activation is required to suppress pro-apoptotic pathways, which is beneficial for the pathogen, while (2) robust NF- $\mathrm{B}$ activation would induce the expression of pro-inflammatory cytokines, ultimately leading to pathogen clearance from the host.

Finally, to identify C. burnetii factors that modulate NF$\kappa \mathrm{B}$ signaling during infection, we investigated whether the C. burnetii T4BSS was involved. In a series of experiments (Figures 5A-D and Figures S1A,B) we demonstrate that bacteria lacking a functional T4BSS do not modulate NF- $\kappa \mathrm{B}$ activation during infection. This suggests that C. burnetii uses T4BSS effectors to either directly or indirectly modulate host NF-кB activity. Multiple studies indicate that C. burnetii T4BSS effectors include proteins with eukaryotic-like domains, including ankyrin repeat domains, tetratricopeptide repeats, coiled-coil domains, leucine-rich repeats, GTPase domains, ubiquitination-related motifs, and multiple kinases and phosphatases (Pan et al., 2008; Voth et al., 2009; Chen et al., 2010; Toman et al., 2012; van Schaik et al., 2013). Importantly, a significant number of C. burnetii T4BSS effectors are translocated into the host cell cytoplasm when expressed in a surrogate L. pneumophila system (Pan et al., 2008; Voth et al., 2009; Chen et al., 2010; Toman et al., 2012; van Schaik et al., 2013). Distinct T4BSS effectors associate with the PV membrane, microtubules, mitochondria,

\section{REFERENCES}

Abu-Zant, A., Jones, S., Asare, R., Suttles, J., Price, C., Graham, J., et al. (2007). Anti-apoptotic signalling by the Dot/Icm secretion system of L. pneumophila. Cell Microbiol. 9, 246-264. doi: 10.1111/j.1462-5822.2006.00785.x

Amara, A. B., Bechah, Y., and Mege, J.-L. (2012). "Immune response and Coxiella burnetii invasion," in Coxiella burnetii: Recent Advances and New Perspectives in Research of the Q Fever Bacterium, eds R. Toman, A. R. Heinzen, E. J. Samuel, and J.-L. Mege (Dordrecht: Springer Netherlands), 287-298.

Andoh, M., Zhang, G., Russell-Lodrigue, K. E., Shive, H. R., Weeks, B. R., and Samuel, J. E. (2007). T cells are essential for bacterial clearance, and gamma interferon, tumor necrosis factor alpha, and B cells are crucial for and the nucleus (Pan et al., 2008; Voth et al., 2009; Chen et al., 2010; Toman et al., 2012; Larson et al., 2013, 2015; Weber et al., 2013; van Schaik et al., 2013; Weber et al., 2016). However, the specific function of the vast majority of confirmed and putative C. burnetii T4BSS effectors remains unknown. Interestingly, C. burnetii's close phylogenetic relative, L. pneumophila, regulates host NF- $\kappa \mathrm{B}$ activation using more than 10 Dot/Icm-dependent effectors (Rahman and McFadden, 2011; Shin, 2012). As NF-кB is one of the principal regulators of the host immune response, identifying and characterizing C. burnetii T4BSS effectors that modulate this pathway and thoroughly characterizing the mechanism of NF- $\kappa$ B modulation will significantly contribute to our understanding of C. burnetii pathogenic mechanisms.

\section{AUTHOR CONTRIBUTIONS}

Conceived and designed the experiments: SM, BG, SS, JG, DV, ES. Performed the experiments: SM, BG, SS, JG. Analyzed the data: SM, BG, JG, DV, ES. Wrote the paper: SM, ES.

\section{FUNDING}

This work was supported by NIH grant R15 AI072710 (to ES), NIH grant R01 AI087669 (to DV), and the Arkansas Biosciences Institute (to DV).

\section{SUPPLEMENTARY MATERIAL}

The Supplementary Material for this article can be found online at: http://journal.frontiersin.org/article/10.3389/fcimb. 2016.00188/full\#supplementary-material

Figure S1 | C. burnetii uses Dot/lcm T4BSS to modulate NF-kB signaling. (A) Immunofluorescent image showing localization of GFP-RelA (green). C. burnetii was visualized by Alexa-555 (red), and DNA/Nuclei with Dapi (blue). HeLa cells transiently transfected with GFP-RelA (green) vector were infected with the indicated C. burnetii strains for $24 \mathrm{~h}$. (A-C) Uninfected cells. (D-G,I-L,N-Q,S-V) Cells infected with the indicated $C$. burnetii strain in which GFP-RelA and DAPI co-localize. Arrows indicate co-localization. (H,M,R, W) Merged micrographs representing cells infected with the indicated $C$. burnetii strain where GFP-RelA did not co-localize with DAPI. Bar, $10 \mu \mathrm{m}$. (B) Quantification of GFP-RelA/DAPI co-localization. A minimum of 100 transiently transfected Hela cells from each of three separate experiments was counted to determine GFP-RelA/DAPI co-localization. Error bars show $\pm \mathrm{SD}$. Statistically significant differences $\left({ }^{*} P<\right.$ 0.05 , Student's $t$-test) are shown when samples are compared to $\mathrm{U}-\mathrm{Cm}$ at $24 \mathrm{hpi}$.

disease development in Coxiella burnetii infection in mice. Infect. Immun. 75, 3245-3255. doi: 10.1128/IAI.01767-06

Bartfeld, S., Engels, C., Bauer, B., Aurass, P., Flieger, A., Brüggemann, H., et al. (2009). Temporal resolution of two-tracked NF-кB activation by Legionella pneumophila. Cell. Microbiol. 11, 1638-1651. doi: 10.1111/j.1462-5822.2009.01354.x

Beare, P. A., Larson, C. L., Gilk, S. D., and Heinzen, R. A. (2012). Two systems for targeted gene deletion in Coxiella burnetii. Appl. Environ. Microbiol. 78, 4580-4589. doi: 10.1128/AEM.00881-12

Beinke, S., and Ley, S. C. (2004). Functions of NF- $\mathrm{KB} 1$ and NF- $\mathrm{\kappa B} 2$ in immune cell biology. Biochem. J. 382, 393-409. doi: 10.1042/BJ20040544

Benoit, M., Barbarat, B., Bernard, A., Olive, D., and Mege, J.-L. (2008). Coxiella burnetii, the agent of $\mathrm{Q}$ fever, stimulates an atypical M2 
activation program in human macrophages. Eur. J. Immunol. 38, 1065-1070. doi: 10.1002/eji.200738067

Bhavsar, A. P., Guttman, J. A., and Finlay, B. B. (2007). Manipulation of host-cell pathways by bacterial pathogens. Nature 449, 827-834. doi: 10.1038 /nature 06247

Böhme, L., and Rudel, T. (2009). Host cell death machinery as a target for bacterial pathogens. Microbes Infect. 11, 1063-1070. doi: 10.1016/j.micinf.2009.08.014

Bonizzi, G., and Karin, M. (2004). The two NF-кB activation pathways and their role in innate and adaptive immunity. Trends Immunol. 25, 280-288. doi: 10.1016/j.it.2004.03.008

Chen, C., Banga, S., Mertens, K., Weber, M. M., Gorbaslieva, I., Tan, Y., et al. (2010). Large-scale identification and translocation of type IV secretion substrates by Coxiella burnetii. Proc. Natl. Acad. Sci. U.S.A. 107, 21755-21760. doi: $10.1073 /$ pnas. 1010485107

Clifton, D. R., Goss, R. A., Sahni, S. K., van Antwerp, D., Baggs, R. B., Marder, V. J., et al. (1998). NF-кB-dependent inhibition of apoptosis is essential for host cell survival during Rickettsia rickettsii infection. Proc. Natl. Acad. Sci. U.S.A. 95, 4646-4651. doi: 10.1073/pnas.95.8.4646

Coleman, S. A., Fischer, E. R., Howe, D., Mead, D. J., and Heinzen, R. A. (2004). Temporal analysis of Coxiella burnetii morphological differentiation. J. Bacteriol. 186, 7344-7352. doi: 10.1128/JB.186.21.7344-7352.2004

Dhiman, R., Raje, M., and Majumdar, S. (2007). Differential expression of NF-кB in mycobacteria infected THP-1 affects apoptosis. Biochim. Biophys. Acta 1770, 649-658. doi: 10.1016/j.bbagen.2006.11.016

Dijkstra, F., van der Hoek, W., Wijers, N., Schimmer, B., Rietveld, A., Wijkmans, C. J., et al. (2012). The 2007-2010 Q fever epidemic in the Netherlands: characteristics of notified acute $Q$ fever patients and the association with dairy goat farming. FEMS Immunol. Med. Microbiol. 64, 3-12. doi: 10.1111/j.1574-695X.2011.00876.x

Enserink, M. (2010). Questions abound in Q-fever explosion in the Netherlands. Science 327, 266-267. doi: 10.1126/science.327.5963.266-a

Graham, J. G., Winchell, C. G., Kurten, R. C., and Voth, D. E. (2016). Development of an ex vivo tissue platform to study the human lung response to Coxiella burnetii. Infect. Immun. 84, 1438-1445. doi: 10.1128/IAI.00012-16

Heinzen, R. A., Hackstadt, T., and Samuel, J. E. (1999). Developmental biology of Coxiella burnettii. Trends Microbiol. 7, 149-154. doi: 10.1016/S0966-842X(99)01475-4

Hoffmann, A., and Baltimore, D. (2006). Circuitry of nuclear factor $\kappa$ B signaling. Immunol. Rev. 210, 171-186. doi: 10.1111/j.0105-2896.2006.00375.x

Honstettre, A., Ghigo, E., Moynault, A., Capo, C., Toman, R., Akira, S., et al. (2004). Lipopolysaccharide from Coxiella burnetii is involved in bacterial phagocytosis, filamentous actin reorganization, and inflammatory responses through Tolllike receptor 4. J. Immunol. 172, 3695-3703. doi: 10.4049/jimmunol.172. 6.3695

Karakousis, P. C., Trucksis, M., and Dumler, J. S. (2006). Chronic Q fever in the United States. J. Clin. Microbiol. 44, 2283-2287. doi: 10.1128/JCM. 02365-05

Kempf, V. A. J., Schairer, A., Neumann, D., Grassl, G. A., Lauber, K., Lebiedziejewski, M., et al. (2005). Bartonella henselae inhibits apoptosis in mono mac 6 cells. Cell. Microbiol. 7, 91-104. doi: 10.1111/j.1462-5822.2004. 00440.x

Lamkanfi, M., and Dixit, V. M. (2010). Manipulation of host cell death pathways during microbial infections. Cell Host Microbe 8, 44-54. doi: 10.1016/j.chom.2010.06.007

Larson, C. L., Beare, P. A., Howe, D., and Heinzen, R. A. (2013). Coxiella burnetii effector protein subverts clathrin-mediated vesicular trafficking for pathogen vacuole biogenesis. Proc. Natl. Acad. Sci. U. S. A. 110, E4770-E4779. doi: 10.1073/pnas.1309195110

Larson, C. L., Beare, P. A., Voth, D. E., Howe, D., Cockrell, D. C., Bastidas, R. J., et al. (2015). Coxiella burnetii effector proteins that localize to the parasitophorous vacuole membrane promote intracellular replication. Infect. Immun. 83, 661-670. doi: 10.1128/IAI.02763-14

Lu, Y.-C., Yeh, W.-C., and Ohashi, P. S. (2008). LPS/TLR4 signal transduction pathway. Cytokine 42, 145-151. doi: 10.1016/j.cyto.2008.01.006

Mahapatra, S., Ayoubi, P., and Shaw, E. (2010). Coxiella burnetii nine mile II proteins modulate gene expression of monocytic host cells during infection. BMC Microbiol. 10:244. doi: 10.1186/1471-2180-10-244

Maurin, M., and Raoult, D. (1999). Q fever. Clin. Microbiol. Rev. 12, 518-553.
McQuiston, J. H., and Childs, J. E. (2002). Q fever in humans and animals in the United States. Vector Borne Zoonotic Dis. 2, 179-191. doi: $10.1089 / 15303660260613747$

McQuiston, J. H., Childs, J. E., and Thompson, H. A. (2002). Q fever. JAVMA 221, 796-799. doi: 10.2460/javma.2002.221.796

Meghari, S., Bechah, Y., Capo, C., Lepidi, H., Raoult, D., Murray, P. J., et al. (2008). Persistent Coxiella burnetii infection in mice overexpressing IL-10: an efficient model for chronic Q fever pathogenesis. PLoS Pathog. 4:e23. doi: 10.1371/journal.ppat.0040023

Meghari, S., Capo, C., Raoult, D., and Mege, J. L. (2006). Deficient transendothelial migration of leukocytes in Q fever: the role played by interleukin-10. J. Infect. Dis. 194, 365-369. doi: 10.1086/505227

Meghari, S., Honstettre, A., Lepidi, H., Ryffel, B., Raoult, D., and Mege, J. L. (2005). TLR2 is necessary to inflammatory response in Coxiella burnetii infection. Ann. N.Y. Acad. Sci. 1063, 161-166. doi: 10.1196/annals.1355.025

Miller, J. D., Shaw, E. I., Thompson, H. A., Anderson, B., Friedman, H., and Bendinelli, M. (eds.). (2006). “Coxiella burnetii, Q fever, and bioterrorism," in Microorganisms and Bioterrorism (New York, NY: Springer), 181-208.

Moos, A., and Hackstadt, T. (1987). Comparative virulence of intra- and interstrain lipopolysaccharide variants of Coxiella burnetii in the guinea pig model. Infect. Immun. 55, 1144-1150.

Morgan, J. K., Luedtke, B. E., and Shaw, E. I. (2010). Polar localization of the Coxiella burnetii type IVB secretion system. FEMS Microbiol. Lett. 305, 177-183. doi: 10.1111/j.1574-6968.2010.01926.x

Newton, H. J., Kohler, L. J., McDonough, J. A., Temoche-Diaz, M., Crabill, E., Hartland, E. L., et al. (2014). A screen of Coxiella burnetii mutants reveals important roles for Dot/Icm effectors and host autophagy in vacuole biogenesis. PLoS Pathog. 10:e1004286. doi: 10.1371/journal.ppat.1004286

Omsland, A., Cockrell, D. C., Howe, D., Fischer, E. R., Virtaneva, K., Sturdevant, D. E., et al. (2009). Host cell-free growth of the Q fever bacterium Coxiella burnetii. Proc. Natl. Acad. Sci. U.S.A. 106, 4430-4434. doi: 10.1073/pnas.0812074106

Pan, X., Lührmann, A., Satoh, A., Laskowski-Arce, M. A., and Roy, C. R. (2008). Ankyrin repeat proteins comprise a diverse family of bacterial type IV effectors. Science 320, 1651-1654. doi: 10.1126/science.1158160

Park, J. M., Greten, F. R., Wong, A., Westrick, R. J., Simon, J. S., Arthur, C. S., et al. (2005). Signaling pathways and genes that inhibit pathogen-induced macrophage apoptosis - CREB and NF- $\mathrm{KB}$ as key regulators. Immunity 23, 319-329. doi: 10.1016/j.immuni.2005.08.010

Perkins, N. D. (2007). Integrating cell-signalling pathways with NF-кB and IKK function. Nat. Rev. Mol. Cell Biol. 8, 49-62. doi: 10.1038/nrm2083

Rahman, M. M., and McFadden, G. (2006). Modulation of tumor necrosis factor by microbial pathogens. PLoS Pathog. 2:e4. doi: 10.1371/journal.ppat.0020004

Rahman, M. M., and McFadden, G. (2011). Modulation of NF-кB signalling by microbial pathogens. Nat. Rev. Microbiol. 9, 291-306. doi: $10.1038 /$ nrmicro2539

Raoult, D., and Marrie, T. (1995). Q fever. Clin. Infect. Dis. 20, 489-495; quiz 496. doi: $10.1093 /$ clinids/20.3.489

Ren, Q., Robertson, S. J., Howe, D., Barrows, L. F., and Heinzen, R. A. (2003). Comparative DNA microarray analysis of host cell transcriptional responses to infection by Coxiella burnetii or Chlamydia trachomatis. Ann. N.Y. Acad. Sci. 990, 701-713. doi: 10.1111/j.1749-6632.2003.tb07447.x

Sakurai, H., Suzuki, S., Kawasaki, N., Nakano, H., Okazaki, T., Chino, A., et al. (2003). Tumor necrosis factor- $\alpha$-induced IKK phosphorylation of NF- $\kappa$ B p65 on serine 536 is mediated through the TRAF2, TRAF5, and TAK1 signaling pathway. J. Biol. Chem. 278, 36916-36923. doi: 10.1074/jbc.M301598200

Schneider, C. A., Rasband, W. S., and Eliceiri, K. W. (2012). NIH Image to ImageJ: 25 years of image analysis. Nat. Methods 9, 671-675. doi: 10.1038/nmeth.2089

Schoffelen, T., Sprong, T., Bleeker-Rovers, C. P., Wegdam-Blans, M. C. A., Ammerdorffer, A., Pronk, M. J. H., et al. (2014). A combination of interferon-gamma and interleukin-2 production by Coxiella burnetiistimulated circulating cells discriminates between chronic $Q$ fever and past $Q$ fever. Clin. Microbiol. Infect. 20, 642-650. doi: 10.1111/1469-0691.12423

Shannon, J. G., Howe, D., and Heinzen, R. A. (2005a). Lack of dendritic cell maturation following infection by Coxiella burnetii synthesizing different lipopolysaccharide chemotypes. Ann. N.Y. Acad. Sci. 1063, 154-160. doi: 10.1196/annals.1355.024

Shannon, J. G., Howe, D., and Heinzen, R. A. (2005b). Virulent Coxiella burnetii does not activate human dendritic cells: role of lipopolysaccharide 
as a shielding molecule. Proc. Natl. Acad. Sci. U.S.A. 102, 8722-8727. doi: $10.1073 /$ pnas.0501863102

Shin, S. (2012). "Chapter 3 - innate immunity to intracellular pathogens: lessons learned from Legionella pneumophila," in Advances in Applied Microbiology, eds S. Sima and M. G. Geoffrey (New York, NY: Academic Press), 43-71.

Soraya Meghari, B., Capo, C., Georges, G., Raoult, D., and Mege, J.-L. (2006). Coxiella burnetii stimulates production of RANTES and MCP1 by mononuclear cells: modulation by adhesion to endothelial cells and its implication in Q fever. Eur. Cytokine Netw. 17, 253-259. doi: 10.1684/ecn.2006.0041

Toman, R., Heinzen, R. A., Samuel, J. E., and Jean-Louis, M. (2012). Coxiella burnetii: Recent Advances and New Perspectives in Research of the Q Fever Bacterium. New York, NY: Springer.

van Schaik, E. J., Chen, C., Mertens, K., Weber, M. M., and Samuel, J. E. (2013). Molecular pathogenesis of the obligate intracellular bacterium Coxiella burnetii. Nat. Rev. Microbiol. 11, 561-573. doi: 10.1038/nrmicro3049

Viatour, P., Merville, M.-P., Bours, V., and Chariot, A. (2005). Phosphorylation

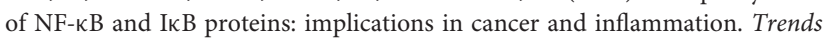
Biochem. Sci. 30, 43-52. doi: 10.1016/j.tibs.2004.11.009

Voth, D. E., Beare, P. A., Howe, D., Sharma, U. M., Samoilis, G., Cockrell, D. C., et al. (2011). The Coxiella burnetii cryptic plasmid is enriched in genes encoding type IV secretion system substrates. J. Bacteriol. 193, 1493-1503. doi: 10.1128/JB.01359-10

Voth, D. E., and Heinzen, R. A. (2007). Lounging in a lysosome: the intracellular lifestyle of Coxiella burnetii. Cell. Microbiol. 9, 829-840. doi: 10.1111/j.1462-5822.2007.00901.x

Voth, D. E., and Heinzen, R. A. (2009). Coxiella type IV secretion and cellular microbiology. Curr. Opin. Microbiol. 12, 74-80. doi: 10.1016/j.mib.2008. 11.005

Voth, D. E., Howe, D., Beare, P. A., Vogel, J. P., Unsworth, N., Samuel, J. E., et al. (2009). The Coxiella burnetii ankyrin repeat domain-containing protein family is heterogeneous with C-terminal truncations that influence Dot/Icm-mediated secretion. J. Bacteriol. 191, 4232-4242. doi: 10.1128/jb.01656-08

Voth, D. E., Howe, D., and Heinzen, R. A. (2007). "Coxiella burnetii inhibits apoptosis and modulates cell survival signaling in macrophages," in FASEB Microbial Pathogenesis Meeting: NIH Rocky Mountain Laboratory (Hamilton, MT).
Wahl, C., Oswald, F., Simnacher, U., Weiss, S., Marre, R., and Essig, A. (2001). Survival of Chlamydia pneumoniae-infected mono mac 6 cells is dependent on NF-кB binding activity. Infect. Immun. 69, 7039-7045. doi: 10.1128/IAI.69.11.7039-7045.2001

Weber, M. M., Chen, C., Rowin, K., Mertens, K., Galvan, G., Zhi, H., et al. (2013). Identification of Coxiella burnetii type IV secretion substrates required for intracellular replication and coxiella-containing vacuole formation. J. Bacteriol. 195, 3914-3924. doi: 10.1128/JB.00071-13

Weber, M. M., Faris, R., McLachlan, J., Tellez, A., Wright, W. U., Galvan, G., et al. (2016). Modulation of the host transcriptome by Coxiella burnetii nuclear effector Cbu1314. Microbes Infect. 18, 336-345. doi: 10.1016/j.micinf.2016.01.003

Wielders, C. C. H., van Loenhout, J. A. F., Morroy, G., Rietveld, A., Notermans, D. W., Wever, P. C., et al. (2015). Long-term serological follow-up of acute Q-fever patients after a large epidemic. PLOS ONE 10:e0131848. doi: 10.1371/journal.pone.0131848

Zamboni, D. S., Campos, M. A., Torrecilhas, A. C., Kiss, K., Samuel, J. E., Golenbock, D. T., et al. (2004). Stimulation of toll-like receptor 2 by Coxiella burnetii is required for macrophage production of pro-inflammatory cytokines and resistance to infection. J. Biol. Chem. 279, 54405-54415. doi: 10.1074/jbc.M410340200

Zhang, G., Russell-Lodrigue, K. E., Andoh, M., Zhang, Y., Hendrix, L. R., and Samuel, J. E. (2007). Mechanisms of vaccine-induced protective immunity against Coxiella burnetii infection in BALB/c mice. J. Immunol. 179, 8372-8380. doi: 10.4049/jimmunol.179.12.8372

Conflict of Interest Statement: The authors declare that the research was conducted in the absence of any commercial or financial relationships that could be construed as a potential conflict of interest.

Copyright (c) 2016 Mahapatra, Gallaher, Smith, Graham, Voth and Shaw. This is an open-access article distributed under the terms of the Creative Commons Attribution License (CC BY). The use, distribution or reproduction in other forums is permitted, provided the original author(s) or licensor are credited and that the original publication in this journal is cited, in accordance with accepted academic practice. No use, distribution or reproduction is permitted which does not comply with these terms. 